\title{
Urban-rural and socioeconomic variations in lifetime prevalence of symptoms of sexually transmitted infections among Bangladeshi adolescents
}

\author{
Mohammad Showkat Gani ${ }^{1 *}$, Ahmed Mushtaque Raza Chowdhury ${ }^{2,3}$ and Lennarth Nyström ${ }^{4}$
}

\begin{abstract}
Aim: To identify socioeconomic and urban-rural variations in self-reported lifetime prevalence of symptoms of sexually transmitted infections (STI).

Methods: This cross-sectional study used data from the Bangladesh Adolescents Survey 2005 conducted on 11,986 adolescents, using a cluster sampling methods. Data were analysed using SPSS applying principle components analysis, multivariate logistic regression analysis, and prevalence ratio (PR) with 95\% confidence interval (Cl).

Results: Self-reported lifetime prevalence of STI symptoms was 11.6\%. Urban adolescents had $11 \%$ lower prevalence than their rural counterparts $(P R(U / R)=0.89 ; 95 \% \mathrm{Cl}=0.79-1.00)$. Probability of self-reported lifetime symptoms of STI was highest among 20-24 years old income-generating male educated workers of mid-socioeconomic status living in rural areas (0.31).

Conclusions: The residence (urban-rural) factor is more influential than the socioeconomic factor. Simpler and cheaper mode of screening and case finding tools for STIs would greatly help. Health promotion and education programs can decrease the adolescents' vulnerability to sexually transmitted diseases.
\end{abstract}

Keywords: STI, Lifetime prevalence, Urban-rural, Adolescents, Bangladesh

\section{Introduction}

Sexually transmitted infections (STI), including acquired immunodeficiency syndrome, are influenced by a number of biological and medical factors on the one hand and geographical, sociocultural or political factors on the other $[1,2]$. Globalization, involving development of trade and movement of both goods and humans across countries and territories, is also being postulated as a major factor in the spread of infectious diseases worldwide [3]. In Bangladesh, nearly one-third of the population is in the 10 to 24-year age group [4]. The vast majority of this section is unaware of the risk of STIs and human immunodeficiency virus (HIV). The situation in Bangladesh, as elsewhere in the world, is getting critical as adolescents

\footnotetext{
* Correspondence: showkat.gani@brac.net

${ }^{1}$ Health and Population Research Unit, Research and Evaluation Division, BRAC, 15th Floor, BRAC Centre, 75 Mohakhali, Dhaka 1212, Bangladesh
} Full list of author information is available at the end of the article usually do not have access to basic information on sexual and reproductive health $(\mathrm{SRH})$, skills in negotiating sexual relationships, and access to affordable SRH services [5,6]. Although PIACT Bangladesh, a non government organization, has worked with the National Curriculum and Textbook Board (NCTB) of Bangladesh to incorporate HIV modules in the curriculum of grades 6 to 10 , but unfortunately this issue has not yet been included in the curriculum $[7,8]$. Several studies revealed that a section of adolescents tend to engage in high-risk activities such as visiting commercial sex workers without using condoms, and thus suffer from STIs as a consequence $[9,10]$. It has been reported that STIs substantially facilitated the rapid and extensive transmission of HIV infections [11]. However, this issue is being given high priority in Bangladesh [12,13].

The World Health Organization has estimated that in 1999 there were 340 million incidences of STIs (gonorrhoea, 
chlamydial infection, syphilis, and trichomoniasis) among the 15-49-year-age group in the world, the highest concentration in Asia [14]. STIs are currently recognized as the major health and economic burdens for many developing and developed countries [14,15]. Thus, the control of STIs is important not only to prevent complications from these infections but also to prevent HIV transmission. In Bangladesh, several studies have assessed adolescents knowledge $[9,10,16,17]$ and estimated the seroprevalence of STIs and reproductive tract infections (RTIs) in both the general population and the high-risk groups [18-21]. However, there is no nationwide study on the prevalence of lifetime symptoms (persons known to have had the disease for at least part of their life) [22] of STIs. Therefore, this study aims to estimate the prevalence of self-reported lifetime symptoms of STIs, and the impact of socioeconomic, demographic and urban-rural factors on the risk of STIs among the 12 to 24year age group of population in Bangladesh.

\section{Methods}

\section{Study design}

This cross-sectional study used data from the Bangladesh Adolescents Survey 2005.

\section{Study area}

Bangladesh, covering an area of $147,570 \mathrm{~km}^{2}$, is one of the most densely populated countries $(1,114$ population $/ \mathrm{km}^{2}$ ) in the world and ranked 129th in the human development index [23]. It is surrounded by India and the Bay of Bengal, and has a tropical climate [4]. Bangladesh is divided into six administrative divisions,
64 districts, 507 sub-districts, 87,928 villages and 8048 mahallas (the smallest identifiable administrative unit in urban areas) [4].

\section{Sampling procedure}

A two-stage cluster sample survey was done in all the six divisions. The sample size for each division was planned to get sufficient precision in the estimates by sex and residence (urban/rural areas).

The Bangladesh Bureau of Statistics (BBS) estimated that a total of 1,000 primary sampling units (PSU) would be sufficient to estimate the demographic indicators for Sample Vital Registration System at district level, and thus formed a sampling frame known as the Integrated Multi-Purpose Master Sample [24]. The survey technique mainly followed the Bangladesh Demographic and Health Survey (BDHS) [25] which uses the BBS sampling frame (Figure 1). Each PSU consists of 200 households. In rural areas, a village is used as a PSU, but in some other parts of the country, the big village or mauza (a geographical boundary consisting of $\geq 1$ village) is used as a PSU. In urban areas, the PSU is at the mahalla level. Figure 1 shows the sampling procedure.

\section{Training of interviewers}

One hundred and twenty graduates were preliminarily selected for a 2-week training in two batches. A training manual was developed. Three experienced researchers facilitated the training sessions through theoretical and practical lessons on data collection. Finally, 110 interviewers were selected, half of whom were females.

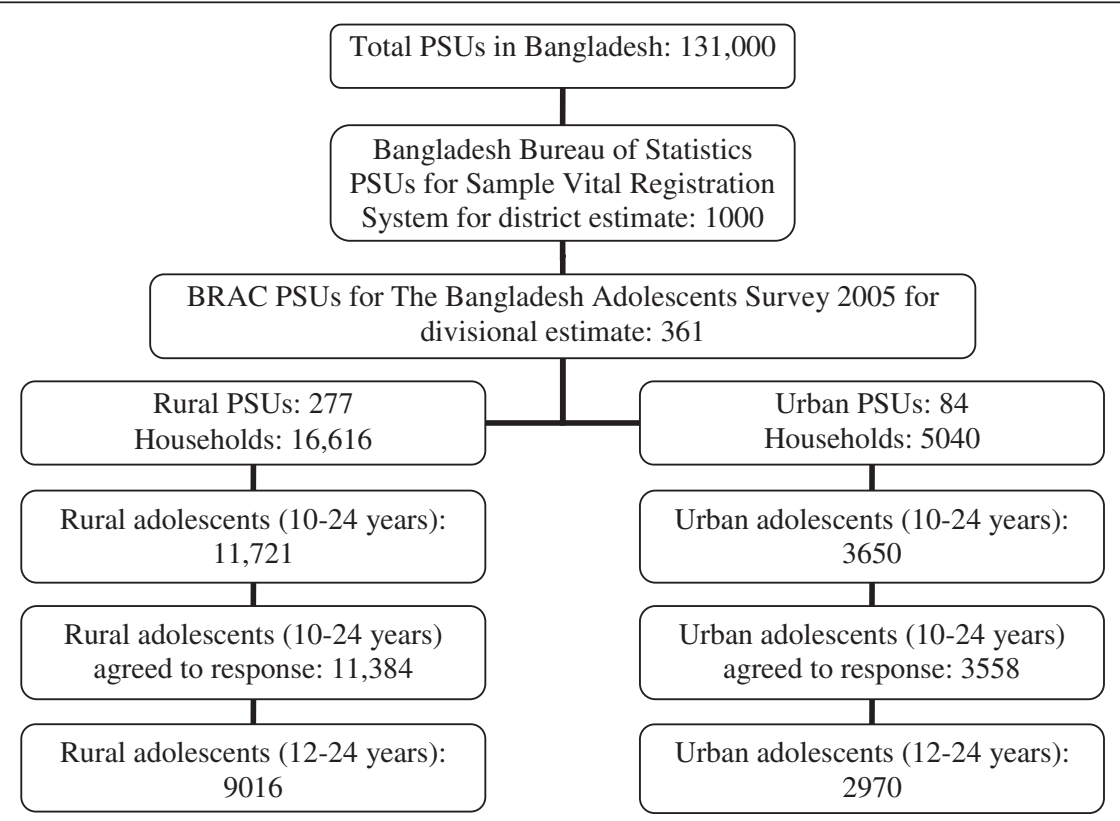

Figure 1 Sampling frame of the study. 


\section{Measure instrument}

Two questionnaires were developed, one for the household and one for the individual. The household questionnaire contained information on household characteristics, household possessions and amenities, disability and death. The individual questionnaire contained information on adolescents' characteristics and their health, education and livelihood issues. The questionnaires were pretested

The lifetime prevalence of STI symptoms was estimated by asking the question: "As some people can have infections that cause pain, itching, scabies, moles or unusual secretions transmitted to their sexual organs, have you ever felt that you suffer from any such infections?" A person was considered to have had a STI, if he/she ever suffered from any infection that caused pain, itching, scabies, moles or unusual secretions in his/her sexual organ.

\section{Data collection}

The interviewers worked in 20 teams consisting of 4 to 5 members each ( 2 females and 2 males) headed by a supervisor. To form a cluster, listing of 200 successive households started from the northwest corner of the selected village and moved anticlockwise. The list was used for selecting a systematic sample of 60 households. The survey teams drew the map for each cluster showing the location of households in the villages/mahallas. Household and individual information were collected in Bangla language by same-sex interviewers privately and confidentially, particularly for the sample adolescents. If more than one eligible adolescent was in the household, Kish method [26] was used for selecting one of them.

While the survey teams had completed their work in the villages, five monitoring teams, each consisting of one woman and one man monitored the data reliability on a $7 \%$ sub-sample basis in two phases. First, they reinterviewed the randomly selected sub-samples, and discussed with the survey teams regarding the dissimilarities of the application of methods and questionnaire parts. Secondly, they re-interviewed the sub-samples and collected data without sharing with survey teams, to check data quality of the main survey. Two quality controllers worked separately to communicate survey instructions from the principal investigator to interviewers and monitors as well as to ensure logistic support to the teams.

\section{Data generation process}

Data were computerised using the FoxPro. Data cleaning and consistency checks were performed simultaneously by the investigators and the data management team through checking the frequency distribution and the range for all variables, and cross tabulations of linked questions to identify and correct the inconsistencies in the data set.

\section{Statistical analysis}

Data were analysed using SPSS. The household wealth index was calculated according to Filmer and Pritchett [27]. Principal components analysis was used to produce a new set of linearly combined measurements for the household wealth scores, which were classified into quintiles. To compare the lifetime prevalence between urban and rural areas, the prevalence ratio $(\mathrm{PR}(\mathrm{U} / \mathrm{R})$ ) and corresponding 95\% confidence intervals (CI) were calculated by using the formula

$$
e^{\left(\ln (P R) \pm 1.96 \sqrt{\frac{N_{1}-A_{1}}{N_{1} A_{1}}+\frac{N_{0}-A_{0}}{N_{0} A_{0}}}\right),}
$$

where $\mathrm{N}_{1}=$ urban total, $\mathrm{A}_{1}=$ urban cases, $\mathrm{N}_{0}=$ rural total, $\mathrm{A}_{0}=$ rural cases [28].

Multivariate logistic regression [29] was used to estimate the impact of age, sex, education, marriage, occupation, wealth index, and the inhabitants' residential status (urban-rural) on the outcome variable, lifetime symptoms of STIs prevalence in terms of odds ratios (OR) and 95\% CI. The probability of prevalence was calculated from the regression coefficients by using the formula

$$
p=\frac{e^{\left(a+\sum b_{i} x_{i}\right)}}{\left[1+e^{\left(a+\sum b_{i} x_{i}\right)}\right]},
$$

where $\mathrm{p}=$ estimated probability of having lifetime symptoms of STI, $\mathrm{a}=$ intercept, $\mathrm{b}=$ regression coefficient, and $\mathrm{x}=$ explanatory variables.

\section{Ethical issues}

Ethical approval was obtained from the research review committee of BRAC Research and Evaluation Division. Written informed consent in Bengali was sought from all respondents before interviewing, but the illiterate respondents provided thumbprint before a witness. Confidentiality of the respondents' identity was maintained and morally right actions with respondents and community people were ensured.

\section{Results}

During the 5-month survey, 16,616 rural and 5,040 urban households were visited (Figure 1). Of these, 11,721 (71\%) rural and 3,650 (72\%) urban adolescents aged 10-24 years were eligible for this survey. Of them, 11,384 (97\%) rural and 3,558 (98\%) urban adolescents agreed to participate. Of the participating adolescents, 9,016 from rural and 2,970 from urban areas were allowed by their family to be interviewed regarding sexual issues. Thus, 5,119 male 
(97.9\%) and 6,867 female (96.6\%) adolescents participated in the survey.

\section{Basic characteristics}

The mean age was 17.5 years, but the female adolescents and the urban adolescents were significantly older (sex: 17.9 vs. $16.9, \mathrm{p}<.001$, and urban-rural: 17.9 vs. 17.4 , $\mathrm{p}<.001$, respectively) (Table 1). One-third of the adolescents were married (34\%). The urban adolescents spent significantly more years in school than the rural adolescents $(6.4$ vs. 5.4 years, $\mathrm{p}<0.001)$, partly because they were older. Majority of them were students $(36 \%)$ or were involved in domestic (36\%) or money-earning work (24\%). The urban adolescents were more engaged in income-generating work than the rural adolescents (27 vs. $23 \%, \mathrm{p}<0.001)$. The wealth index showed that a significantly higher proportion of rich lived in urban areas compared to that in rural areas (50 vs. $15 \%, \mathrm{p}<0.001$,) (Table 1).

\section{Reported lifetime prevalence of STI symptoms}

The lifetime prevalence of STI symptoms among adolescents was $11.6 \%$, significantly higher in rural areas

Table 1 Socioeconomic characteristics of 12 to 24 years age group by residence

\begin{tabular}{|c|c|c|c|}
\hline \multirow[t]{2}{*}{ Characteristics } & \multicolumn{2}{|c|}{ Residence } & \multirow[t]{2}{*}{ All } \\
\hline & Urban & Rural & \\
\hline \multicolumn{4}{|l|}{ Age in years (\%) } \\
\hline $12-14$ & 24.1 & 28.3 & 27.3 \\
\hline $15-19$ & 37.5 & 39.3 & 38.8 \\
\hline $20-24$ & 38.4 & 32.4 & 33.9 \\
\hline Mean age (years) & 17.9 & 17.4 & 17.5 \\
\hline Sex ratio (M/F) & 0.78 & 0.74 & 0.75 \\
\hline Married (\%) & 30.2 & 35.1 & 33.9 \\
\hline No schooling (\%) & 10.3 & 11.7 & 11.4 \\
\hline Mean years of education & 6.4 & 5.4 & 5.7 \\
\hline \multicolumn{4}{|l|}{ Occupation (\%) } \\
\hline Student & 38.3 & 35.4 & 36.1 \\
\hline Household work & 30.5 & 37.8 & 36.0 \\
\hline Income-generating work ${ }^{a}$ & 27.1 & 22.6 & 23.7 \\
\hline Others $^{\mathrm{b}}$ & 4.1 & 4.2 & 4.2 \\
\hline \multicolumn{4}{|l|}{ Wealth index (\%) } \\
\hline Poorest & 5.6 & 17.8 & 14.8 \\
\hline 2 & 9.1 & 20.7 & 17.8 \\
\hline 3 & 13.9 & 23.9 & 21.4 \\
\hline 4 & 21.4 & 22.7 & 22.4 \\
\hline Rich & 50.0 & 15.0 & 24.0 \\
\hline Total (n) & 2970 & 9016 & 11,986 \\
\hline
\end{tabular}

Note: ${ }^{a}$ All kinds of wage/self employed workers including business. ${ }^{\mathrm{b}}$ Beggar, disabled, and unemployed etc. compared to urban areas (11.9 vs. $10.6 \%, \mathrm{p}=.048)$ (Table 2). The lifetime prevalence of STI increased significantly with increasing age from $5.5 \%$ in the $12-14$ years age group to $12.4 \%$ and $15.6 \%$ respectively in the $15-19$ and 20-24 years age groups. Males had a significantly higher prevalence compared to females ( 14.8 vs. $9.3 \%, \mathrm{p}<$ 0.001 ). The prevalence was significantly higher for the currently married than that of the single adolescents (13.9 vs. $10.4 \%, \mathrm{p}<0.001)$. Among the currently married adolescents, the prevalence also increased significantly with increasing age groups (from 7.9 to $11.8 \%$ to $14.9 \%, \mathrm{p}<0.05$ ), The males had significantly higher prevalence compared to females $(19.2$ vs. $13.3 \%, \mathrm{p}<0.01)$. The prevalence was higher in adolescents involved in income-generating work when compared with that of other occupational groups. There was no trend in the wealth index. To summarise, the significantly higher prevalence was found for the males compared to the females, when particularly considered those adolescents who were currently married (20-24 years) and living in rural areas (19.9 vs. $14.8 \%, \mathrm{p}<0.05)$.

\section{Urban/rural prevalence ratio}

The prevalence ratio for self-reported lifetime symptoms of STI was $11 \%$ lower in the urban adolescents compared to rural adolescents $(\mathrm{PR}=0.89,95 \% \mathrm{CI}=0.79-1.0)$ (Table 2). The urban/rural prevalence ratio $(\mathrm{PR}(\mathrm{U} / \mathrm{R})$ was $<1)$ for almost all categories of socioeconomic and demographic characteristics. The only exception was being separated/divorced/widowed in rural areas $(\mathrm{PR}=2.8$, $95 \% \mathrm{CI}=1.01-7.9$ ).

\section{Multivariate logistic regression analysis}

The likelihood of having reported lifetime symptoms of STI was three times higher for males than females $(\mathrm{OR}=2.9,95 \% \mathrm{CI}=2.4-3.6)$, and increased by age from one in the 12-14 years age group to $2.3(95 \% \mathrm{CI}=1.9$ 2.8 ) and $2.9(95 \% \mathrm{CI}=2.3-3.6)$ in the $15-19$ and $20-24$ years age groups, respectively (Table 3 ). Currently married respondents had a $40 \%$ higher risk than singles $(\mathrm{OR}=1.4 ; 95 \% \mathrm{CI}=1.2-1.7)$.

\section{Probability estimation}

The probability of lifetime prevalence of STI symptoms as outcomes of the effect of various combinations of factors is shown in Figure 2. The probability was low among 12-14 years old female adolescent household workers with no schooling or having primary education, from either poorest or rich living in urban areas $(\mathrm{p}=0.02)$ (Figure 2). The highest prevalence was found for the 20-24 years old males with higher education and income, from the middle socioeconomic group living in rural areas $(\mathrm{p}=0.31)$. 
Table 2 Number of subjects, prevalence and urban/rural prevalence ratio (PR(U/R)) with $95 \%$ confidence intervals (CI) of lifetime symptoms of STIs of 12 to 24 years age group by socioeconomic factors

\begin{tabular}{|c|c|c|c|c|c|c|}
\hline \multirow[t]{2}{*}{ Characteristic } & \multicolumn{2}{|c|}{ No. of subjects } & \multicolumn{3}{|c|}{ Prevalence (\%) } & \multirow{2}{*}{$\begin{array}{l}\text { PR (U/R) } \\
95 \% \mathrm{Cl}\end{array}$} \\
\hline & Urban (U) & Rural (R) & All & Urban (U) & Rural (R) & \\
\hline \multicolumn{7}{|l|}{ Age in years } \\
\hline $12-14$ & 717 & 2551 & 5.5 & 5.2 & 5.6 & $0.93(0.65-1.3)$ \\
\hline 15-19 & 1114 & 3542 & 12.4 & 10.7 & 13.0 & $0.82(0.68-1.00)$ \\
\hline $20-24$ & 1139 & 2923 & 15.6 & 14.0 & 16.3 & $0.86(0.73-1.01)$ \\
\hline$p$ value ${ }^{a}$ & & & $<0.001$ & $<0.001$ & $<0.001$ & \\
\hline \multicolumn{7}{|l|}{ Sex } \\
\hline Male & 1298 & 3821 & 14.8 & 13.2 & 15.3 & $0.86(0.73-1.01)$ \\
\hline Female & 1672 & 5195 & 9.3 & 8.6 & 9.5 & $0.91(0.76-1.09)$ \\
\hline$p$ value ${ }^{b}$ & & & $<0.001$ & $<0.001$ & $<0.001$ & \\
\hline \multicolumn{7}{|l|}{ Education } \\
\hline No schooling & 297 & 1082 & 12.8 & 11.4 & 13.2 & $0.87(0.61-1.2)$ \\
\hline Primary & 898 & 3661 & 10.6 & 10.7 & 10.6 & $1.0(0.81-1.2)$ \\
\hline Secondary or higher & 1775 & 4273 & 12.1 & 10.4 & 12.8 & $0.82(0.70-0.96)$ \\
\hline p value ${ }^{a}$ & & & 0.024 & 0.86 & 0.006 & \\
\hline \multicolumn{7}{|l|}{ Marital status } \\
\hline Single & 2050 & 5789 & 10.4 & 9.5 & 10.7 & $0.88(0.76-1.03)$ \\
\hline Currently married & 897 & 3162 & 13.9 & 12.8 & 14.2 & $0.90(0.74-1.1)$ \\
\hline Separated/Divorced/Widowed & 23 & 65 & 13.6 & 26.1 & 9.2 & $2.8(1.01-7.9)$ \\
\hline$p$ value ${ }^{a}$ & & & $<0.001$ & 0.001 & 0.0013 & \\
\hline \multicolumn{7}{|l|}{ Occupation } \\
\hline Student & 1137 & 3189 & 9.0 & 7.7 & 9.4 & $0.81(0.64-1.02)$ \\
\hline Household work & 905 & 3410 & 11.8 & 11.5 & 11.8 & $0.97(0.79-1.2)$ \\
\hline Income-generating Work & 805 & 2035 & 15.2 & 13.3 & 16.0 & $0.83(0.68-1.02)$ \\
\hline Unemployed/others & 123 & 382 & 12.7 & 13.8 & 12.3 & $1.1(0.67-1.9)$ \\
\hline$p$ value ${ }^{a}$ & & & $<0.001$ & $<0.001$ & $<0.001$ & \\
\hline \multicolumn{7}{|l|}{ Wealth index } \\
\hline Poorest & 165 & 1604 & 9.5 & 7.3 & 9.7 & $0.75(0.43-1.3)$ \\
\hline 2 & 271 & 1866 & 11.8 & 11.1 & 12.0 & $0.93(0.65-1.3)$ \\
\hline 3 & 412 & 2156 & 13.0 & 15.3 & 12.6 & $1.2(0.94-1.6)$ \\
\hline 4 & 637 & 2048 & 13.5 & 13.7 & 13.4 & $1.0(0.81-1.3)$ \\
\hline Rich & 1485 & 1342 & 9.7 & 8.3 & 11.3 & $0.74(0.59-0.92)$ \\
\hline$p$ value ${ }^{a}$ & & & $<0.001$ & $<0.001$ & 0.0098 & \\
\hline All & 2970 & 9016 & 11.6 & 10.6 & 11.9 & $0.89(0.79-1.00)$ \\
\hline
\end{tabular}

Abbreviation: STI sexually transmitted infection.

${ }^{a} \mathrm{p}$ value is the test of heterogeneity; ${ }^{\mathrm{b}} \mathrm{p}$ value for test of differences in the prevalence by sex.

\section{Discussion}

This study shows that the self-reported lifetime prevalence of STI symptoms among adolescents in Bangladesh is high and varies by their place of residence, and socioeconomic and demographic factors. This information is useful for the policy-makers to develop strategies to prevent and control sexually transmitted diseases.
This study confirms a high lifetime prevalence of STI symptoms is more prominent among males. It also contradicts the misconception, found in one report, that STI prevalence is higher in women, which is possibly due to lack of awareness and practice of personal hygiene [30]. Highest prevalence was found in currently married older adolescents (20-24 years) living in rural areas. Studies in Bangladesh and neighbouring countries 


\begin{tabular}{|c|c|c|c|c|}
\hline \multirow[t]{2}{*}{ Factor } & \multicolumn{2}{|c|}{ No. of subjects (STI) } & \multirow[t]{2}{*}{ OR } & \multirow[t]{2}{*}{$95 \% \mathrm{Cl}$} \\
\hline & Yes & No & & \\
\hline \multicolumn{5}{|l|}{ Residence } \\
\hline Urban & 315 & 2655 & 1 & \\
\hline Rural & 1077 & 7939 & 1.13 & $0.98-1.3$ \\
\hline \multicolumn{5}{|l|}{ Age in years } \\
\hline $12-14$ & 179 & 3089 & 1 & \\
\hline 15-19 & 578 & 4078 & 2.3 & $1.9-2.8$ \\
\hline $20-24$ & 635 & 3427 & 2.9 & $2.3-3.6$ \\
\hline \multicolumn{5}{|l|}{ Sex } \\
\hline Female & 756 & 4363 & 1 & \\
\hline Male & 636 & 6231 & 2.9 & $2.3-3.5$ \\
\hline \multicolumn{5}{|l|}{ Education } \\
\hline No schooling & 177 & 1202 & 1 & \\
\hline Primary & 485 & 4074 & 0.98 & $0.81-1.2$ \\
\hline Secondary and higher & 730 & 5318 & 1.03 & $0.84-1.3$ \\
\hline \multicolumn{5}{|l|}{ Marital status } \\
\hline Single & 815 & 7024 & 1 & \\
\hline Currently married & 565 & 3494 & 1.4 & $1.2-1.7$ \\
\hline Separated/Widowed/Divorced & 12 & 76 & 1.7 & $0.90-3.2$ \\
\hline \multicolumn{5}{|l|}{ Occupation } \\
\hline Student & 388 & 3938 & 1 & \\
\hline Household work & 508 & 3807 & 1.3 & $0.98-1.6$ \\
\hline Income-generating work & 432 & 2408 & 0.88 & $0.73-1.1$ \\
\hline Unemployed/others & 64 & 441 & 0.91 & $0.67-1.2$ \\
\hline \multicolumn{5}{|l|}{ Wealth index } \\
\hline Poorest & 168 & 1601 & 1 & \\
\hline 2 & 253 & 1884 & 1.2 & $0.99-1.5$ \\
\hline 3 & 335 & 2233 & 1.3 & $1.1-1.6$ \\
\hline 4 & 362 & 2323 & 1.4 & $1.1-1.7$ \\
\hline Rich & 274 & 2553 & 1.0 & $0.79-1.3$ \\
\hline
\end{tabular}

Abbreviation: STI sexually transmitted infection.

have shown varying prevalence rates of STIs in the general population as well as in high-risk groups [18-20]. Bogaerts et al. [20] detected a low prevalence of Neisseria gonorrhoea and chlamydia infections $(0.5 \%$ and $1.9 \%$ ) among urban female clients in a basic healthcare clinic in Dhaka, while Sabin et al. [18] reported a higher sero-prevalence of current STIs (10.4\% in 15 to 54-year old men and $6.9 \%$ in 15 to 40 -year old women) among slum dwellers in Dhaka, Bangladesh. Similar studies in neighbouring countries reported a higher prevalence than what we found in this study. In Hainan [31], China, Xia et al. found that the lifetime prevalence of STI symptoms among the 18 to 49 -year old married rural women was $39 \%$. The higher prevalence is possibly partly explained by that they were older than the adolescents we studied, and thus had had a longer exposure time. In an urban-based cross-sectional study of residents from low-income communities in Chennai, India [32], the prevalence for self-reported STI symptoms was $16 \%$, higher than that of our study. Reasons for varied results could be due to differences in sampling method, measuring instruments, manner of queries, and way of filling questionnaires.

The prevalence in high-risk groups is higher. A crosssectional study of 18-30 years old street-based female sex workers in Dhaka by Rahman et al. detected 33\% prevalence of syphilis and $46 \%$ prevalence of Neisseria gonorrhoea/chlamydia [33]. Another cross-sectional study estimated the prevalence of syphilis and Neisseria gonorrhoea/chlamydia at $8.5 \%$ and $58 \%$ respectively in 18-25 years old hotel-based female sex workers in Dhaka [21].

Using the Bangladesh adolescents survey 2005 dataset, Gani and Ahmed [17] showed that the adolescents grew up without knowing the facts of SRH, which is prominent among the low educated rural adolescents living in poor households. This pattern is also confirmed in this analysis. This might be because the cultural norms forced the parents/guardians to feel embarrassed or ashamed to discuss these issues with their adolescent children, and that the media is overlooking the issue simply as it involves the issue of sex $[8,21]$. Consequently most of them have had a limited access to reliable and complete SRH information, which is making the adolescents vulnerable. Therefore, the cultural behaviour bias might have been associated with this disease.

Limitations of this study include non-response bias (3\% for all selected adolescents) as it happened against the backdrop of a huge temporary migration of 15 to 24 years old male respondents, particularly for foreign employment [34]. The interviewers found it difficult to determine the exact age of the respondents although the events calendar was used to obtain best estimates. As such some errors cannot be ruled out. The lowest rate of STI symptoms among females might be due to silent infections or any other unknown reasons relating to social stigma of STI. Another limitation is that the self-reported symptoms are not serologically confirmed as found in some other studies [31,32], and, thus non-STI genital symptoms may have been included in the results.

Strengths of this first nationwide adolescents survey is that it permits to draw conclusions regarding the whole country by age, sex and place of residence. Furthermore, the size of the study facilitates precise point estimates with narrow confidence intervals. As the sampling design is similar to the 2004 BDHS [25], it allows comparison of some background indicators for testing data reliability and 


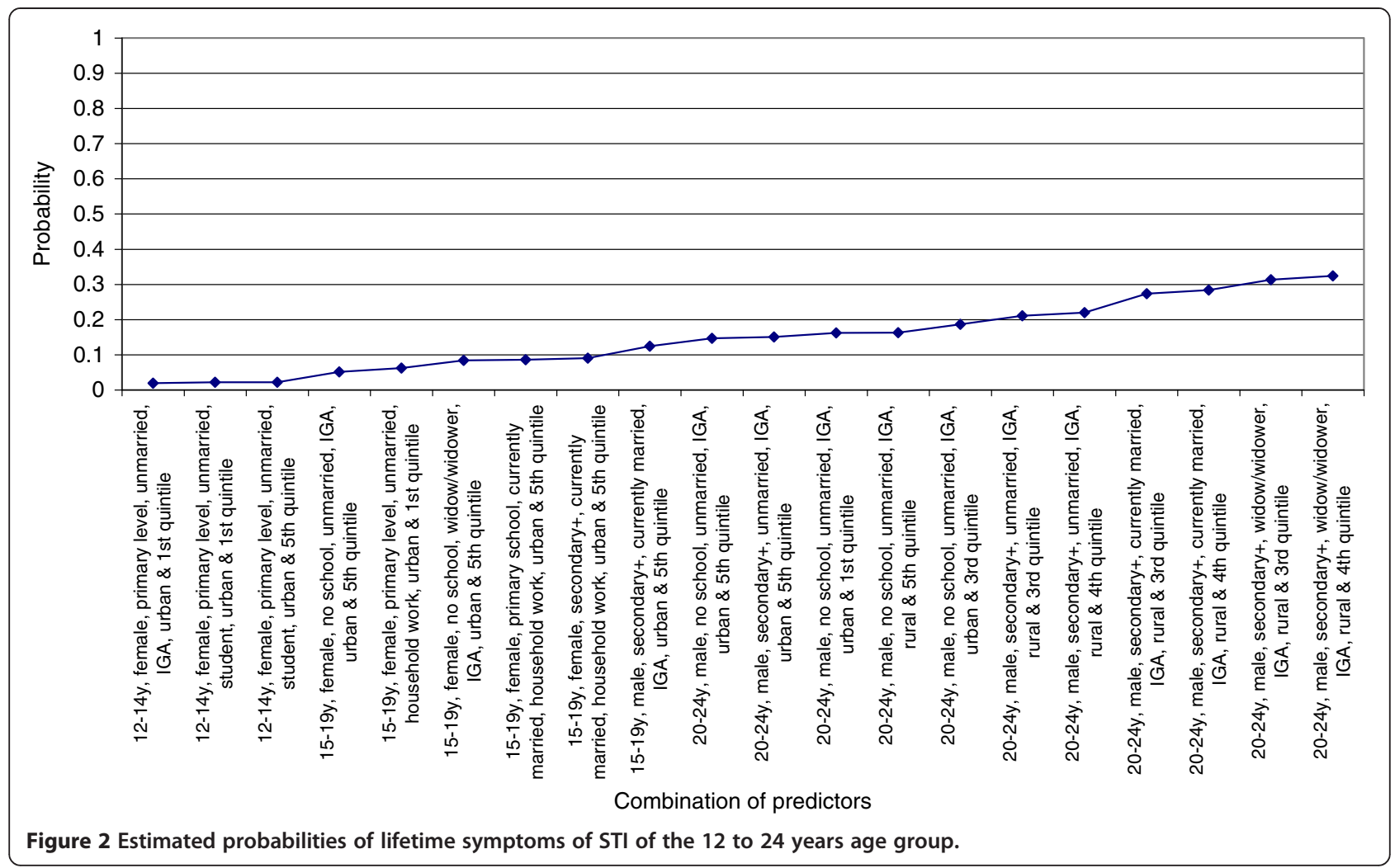

validity of this study. For example, the male/female ratio of this study is consistent with that of the national dataset (0.80 in BAS 2005; 0.85 in BDHS 2004) [25].

\section{Conclusion}

The high self-reported lifetime prevalence of STIs among adolescents reflects the varying living conditions in urban and rural areas, and demographic and socioeconomic characteristics. Older male adolescents with higher education from the middle class socioeconomic background living in rural areas are especially at risk of having the STIs. It thus indicates that STIs are endemic in the entire country. Further research is needed to fully understand the epidemiology of STI in Bangladesh. A prerequisite is a cheap and reliable screening instrument to be able to quickly confirm symptomatic cases. Further research is also needed to identify effective intervention to reduce the STI prevalence in Bangladesh.

Simpler and cheaper mode of screening and case finding tools are urgently required for a clear understanding of the epidemiology of STIs in Bangladesh. Therefore, this simple, inexpensive, and replicable method could also be used to gauge the distribution of self-reported lifetime symptoms of STIs in other countries and, thus, create the basis for a thorough aetiological research on overall STIs and appropriate interventions to address the problem.

\section{Competing interests}

The authors declared no conflict of interest with respect to the research, authorship, and/or publication of this article.

\section{Authors' contributions}

MSG participated in the proposal, design, coordinating the study, performed the statistical analysis, carried out of the study and drafted the manuscript. AMRC participated in the proposal, and drafted the manuscript. LN participated in the proposal, design, coordinating the study, reviewed the statistical analysis and drafted the manuscript. All authors read and approved of the final manuscript.

\section{Acknowledgements}

We thank the BRAC Research and Evaluation Division (BRAC-RED) for allowing us access to database of The Bangladesh Adolescents Survey 2005. This national survey, funded by BRAC Education Programme, is a collaborative initiative between BRAC-RED and the Population Council (USA). We are also grateful to Richard Moreino, executive editor of The Good Morning (Bangladesh) and Hasan Shareef Ahmed, freelance science editor and communication consultant for their editorial support. We would like to thank all those who helped us during preparing this report.

\section{Funding}

The first two authors received no financial support for the research, authorship, and/or publication of this article, but the third author, Lennarth Nyström was supported by the Umeå Centre for Global Health Research via the Swedish Council for Working Life and Social Research Grant \#2006-1512, Umeå University, Sweden.

\section{Author details}

'Health and Population Research Unit, Research and Evaluation Division, BRAC, 15th Floor, BRAC Centre, 75 Mohakhali, Dhaka 1212, Bangladesh. ${ }^{2}$ BRAC Governing Body, BRAC, 75 Mohakhali, Dhaka 1212, Bangladesh. ${ }^{3}$ Population and Family Health, Mailman School of Public Health, Columbia University, Columbia, NY 10032, USA. ${ }^{4}$ Department of Public Health and Clinical Medicine, Epidemiology and Global Health, Umeå University, Umeå SE-901 85, Sweden. 
Received: 14 March 2012 Accepted: 27 June 2014

Published: 16 July 2014

\section{References}

1. Wasserheit JN: Epidemiological synergy. Interrelationships between human immunodeficiency virus infection and other sexually transmitted diseases. Sex Transm Dis 1992, 19:61-77.

2. Mayaud P, Mabey D: Approached to the control of sexually transmitted infections in developing countries: old problems and modern challenges. Sex Transm Infect 2004, 80:174-82.

3. Cameron DW: Internationalism, infectious diseases and international development: there is an elephant in the living room. Int J Infect Dis 2007, 11:3.

4. Bangladesh Bureau of Statistics: Population census 2001. National report (Provisional). Dhaka, Bangladesh: Bangladesh Bureau of Statistics; 2003.

5. Bhuiya I, Chowdhury AH: Prevention of HIV/AIDS Among Young People in Bangladesh: Improving Access to Life Skills Based Sexual and Reproductive Health Education and Condom Services for Male Youth. Dhaka, Bangladesh: National AIDS/STD Programme, Save the Children-USA and Population Council; 2007

6. Wong ML: Preventing adolescents from adopting HIV-related risky sexual behaviours: do we have all the answers? Asia Pac J Public Health 2006, 18(1):1-2.

7. World Health Organization: South-East Asia Regional Office: Adolescent Sexual and Reproductive Health HIV/AIDS among Young People: Compendium of Institutions in Bangladesh. New Delhi, India: World Health Organization (WHO); 2007:38.

8. Prothom Alo (A Daily Bangla Newspaper): The roundtable discussion: adolescent's sexual health: role of guardians. Prothom Alo 2012, January 17:20 (Col 2-5)

9. Joint United Nations Programme on HIV/AIDS and The World Bank: 20 years of HIV/AIDS in Bangladesh: Experiences and Way forward. Dhaka, Bangladesh: Joint United Nations Programme on HIV/AIDS and The World Bank; 2009.

10. Bhuiya I, Rob U, Chowdhury AH, Rahman L, Haque N, Adamchak S, Kahn ME: Improving adolescent reproductive health in Bangladesh. Frontiers in reproductive health. Dhaka, Bangladesh: Population Council; 2004.

11. Robinson NJ, Mulder DW, Auvert B, Hayes RJ: Proportion of HIV infections attributable to other sexually transmitted diseases in a rural Ugandan population: simulation model estimates. Int J Epidemiol 1997, 26:180-9.

12. Government of Bangladesh: National strategic plan for HIV/AIDS 2004-2012. NASP, MOHFW: Dhaka, Bangladesh: Government of Bangladesh; 2004. Available from: http://aidstar-one.com/sites/default/files/prevention/ resources/national_strategic_plans/Bangladesh_04-10.pdf.

13. International Conference on Population and Development (ICPD+5) ; 1999. Available from: http://www.un.org/popin/icpd5.htm.

14. World Health Organization: Global prevalence and incidence of selected curable sexually transmitted infections: overviews and estimates. Geneva, Switzerland: World Health Organization (WHO); 2001.

15. Sangani P, Rutherford G, Wilkinson D: Population-based interventions for reducing sexually transmitted infections, including HIV infection. West Sussex, UK: Cochrane Database Syst Rev: John Wiley \& Sons Ltd; 2004. Issue 3:2-3.

16. Nahar Q, Tuñón C, Houvras I, Gazi R, Reza M, Huq NL, Khuda BE: Reproductive Health Needs of Adolescents in Bangladesh: A Study Report (ICDDR,B Working Paper No. 130). Dhaka, Bangladesh: ICDDR,B: Centre for Health and Population Research; 1999.

17. Gani MS, Ahmed SM: Growing up and reproducing: knowledge and practices of young people in Bangladesh. In Adolescents and youths in Bangladesh: some selected issues (BRAC Research Monograph Series No. 31). Dhaka, Bangladesh: BRAC: Bangladesh Rural Advancement Committee; 2006:73-96

18. Sabin KM, Rahman M, Hawkes S, Ahsan K, Begum L, Black RE, Baqui AH: Sexually transmitted infections prevalence rates in slum communities of Dhaka, Bangladesh. Int J STD AIDS 2003, 14:614-21.

19. Hawkes S, Morison L, Foster S, Gausia K, Chakraborty J, Peeling RW, Mabey $D$ : Reproductive-tract infections in women in low-income, lowprevalence situations: assessment of syndromic management in Matlab, Bangladesh. Lancet 1999, 354:1776-81.

20. Bogaerts J, Ahmed J, Akhter N, Begum N, Rahman M, Nahar S, Van Ranst M, Verhaegen J: Sexually transmitted infections among married women in Dhaka, Bangladesh: unexpected high prevalence of herpes simplex type 2 infection. Sex Transm Infect 2001, 77:114-9.
21. Nessa K, Waris SA, Sultan Z, Monira S, Hossain M, Nahar S, Rahman H, Alam M, Baatsen P, Rahman M: Epidemiology and etiology of sexually transmitted infection among hotel-based sex workers in Dhaka, Bangladesh. J Clin Microbiol 2004, 42:618-21.

22. Last JM: A dictionary of epidemiology. 2nd edition. New York, NY: Oxford University Press; 1988.

23. United Nations Development Programme: Human Development Report 2010, The Real Wealth of Nations: Pathways to Human Development. 20th Anniversary edition. New York, NY: United Nations Development Programme (UNDP); 2010. Available from: http://hdr.undp.org/en/media/

HDR_2010_EN_Tables_reprint.pdf. Published 2010.

24. Bangladesh Bureau of Statistics: Report of sample vital registration system. Dhaka, Bangladesh: Bangladesh Bureau of Statistics (BBS), Planning Division, Ministry of Planning; 2004.

25. National Institute of Population Research and Training, Mitra \& Associates, ORC Macro: Bangladesh Demographic and Health Survey. Dhaka, Bangladesh, and Claverton, MD: National Institute of Population Research and Training (NIPORT), Mitra \& Associates, and Macro International; 2005.

26. Kish $L$ : A procedure for objective respondent selection within the household. J Am Stat Assoc 1949, 44:380-7.

27. Filmer D, Pritchett L: Estimating wealth effects without expenditure data-tears: An application to educational enrollments in states of India (World Bank Policy Research Working Paper No. 1994). Washington, DC: World Bank; 2000.

28. Rothman KJ: Epidemiology: an introduction. 2nd edition. New York: Oxford University Press; 2002.

29. Menard S: Applied Logistic Regression Analysis. Thousand Oaks, CA: Sage; 1995.

30. National Institute of Population Research and Training, Mitra \& Associates, and Macro International: Bangladesh Demographic and Health Survey. Dhaka and Calverton: National Institute of Population Research and Training (NIPORT), Mitra \& Associates, and Macro International; 2009.

31. Xia DY, Liao SS, He QY, Choi KH, Mandel JS: Self-reported symptoms of reproductive tract infections among rural women in Hainan, China: prevalence rates and risk factors. Sex Transm Dis 2004, 31:643-9.

32. Panchanadeswaran S, Johnson SC, Mayer KH, Srikrisnan AK, Sivaram S, Zelaya CE, Go VF, Solomon S, Bentley ME, Celentano DD: Gender differences in the prevalence of sexually transmitted infections and genital symptoms in an urban setting in southern India. Sex Transm Infect 2006, 82:491-5.

33. Rahman M, Alam A, Nessa K, Hossain A, Nahar S, Datta D, Khan SA, Mian RA, Albert MJ: Etiology of sexually transmitted infections among street-based female sex workers in Dhaka, Bangladesh. J Clin Microbiol 2000, 38:1244-6.

34. The Daily Star (A Daily English Newspaper): Young Bangladeshis: The soldiers of fortune. Daily Star 2006, March 13:5. Available from: http:// www.thedailystar.net/2006/03/13/d603131502122.htm.

doi:10.1186/s12930-014-0007-y

Cite this article as: Gani et al:: Urban-rural and socioeconomic variations in lifetime prevalence of symptoms of sexually transmitted infections among Bangladeshi adolescents. Asia Pacific Family Medicine 2014 13:7.

\section{Submit your next manuscript to BioMed Central and take full advantage of:}

- Convenient online submission

- Thorough peer review

- No space constraints or color figure charges

- Immediate publication on acceptance

- Inclusion in PubMed, CAS, Scopus and Google Scholar

- Research which is freely available for redistribution 